\title{
Tecnologia Educacional para ensino médio - BibliVirti
}

\author{
Alynne Raquel S. Pereira, \\ Cynara Lira C. Souza, Luiz Mario F. Cavalcante, Valério Bezerra Leite, \\ Djalmo Pereira C. Junior
}

\begin{abstract}
Departamento de Computação - Faculdade de Ciências Aplicadas e Sociais de Petrolina FACAPE CEP: 56300.000 - Petrolina - PE - Brasil

\{alynneraquel, luizmario72\}@hotmail.com, cynaracarvalho@yahoo.com.br,
valeriobezerra.dev@gmail.com, djalmo.cruz@gmail.com
\end{abstract}

\begin{abstract}
Mobile learning environments (AVAM), like any other software systems need to provide functions which meet stated and implied needs expected by learners and tutors. Therefore, a process for defining requirements for virtual environments of mobile learning has been defined based on the activities of design thinking and creative techniques such as mind mapping, brainstorming, prototyping and personas to find a solution based on the needs of end users. As a result it was proposed an AVAM with access to content and learning materials to assist in the teaching learning process which we call BibliVirti.
\end{abstract}

Resumo. Ambientes de aprendizagem móvel (AVAM), a exemplo de quaisquer outros sistemas de software, precisam prover funções que atendam às necessidades explícitas e implícitas esperadas pelos aprendizes e tutores. Portanto, um processo de elicitação de requisitos para ambientes virtuais de aprendizagem móvel foi definido com base nas atividades do Design Thinking e em técnicas criativas, como mapas mentais, brainstorming, personas $e$ prototipagem para encontrar uma solução baseada nas necessidades dos usuários finais. Como resultado foi proposto um AVAM com acesso a conteúdos e materiais didáticos para auxiliar no processo de ensino aprendizagem o qual denominamos BibliVirti.

\section{Cenário de Uso}

O governo federal criou um projeto chamado Educação digital (PORTAL BRASIL, 2012) e distribuiu tablets nas escolas públicas com o intuito de inserir o apoio da tecnologia no processo de ensino aprendizagem. A proposta da criação desta solução partiu da ideia de se especificar um software que realmente atenda as necessidades dos usuários finais (professores e alunos) e que seja inserida no processo de ensino aprendizagem. Esta aplicação será desenvolvida com intuito de ser instalada nos tablets distribuídos pelo governo.

Foi escolhida uma escola pública do ensino médio para que uma solução de apoio ao processo de ensino e aprendizagem fosse proposta no contexto do experimento. Foram aplicados os processos de levantamento de requisitos com alunos da $2^{\mathrm{a}}$ e $3^{\mathrm{a}}$ séries do ensino médio para buscarem uma solução baseada em tecnologia móvel para apoiar o processo de ensino aprendizagem da escola. 
Na escola identificou-se que a dificuldade dos alunos e professores era o acesso a "conteúdos", por ser uma escola pública, carente de biblioteca e livros, sendo proposta uma solução que foi denominada de BibliVirti. Nem sempre o cotidiano do professor lhe oferece possibilidade para inovar. Esta possibilidade está fora das condições de muitos professores. Como podemos perceber pelo relato professores: "Nós, professores temos muita dificuldade para elaborar materiais didáticos mais adequados a realidade dos alunos. Muitas vezes ficamos só com os livros didáticos que o MEC manda, mesmo sendo inadequado, com linguagem muito distante das realidades dos alunos. Isso leva a um certo desinteresse por parte dos estudantes".

Os participantes envolvidos foram alunos(as) e professores(as) do ensino médio que atuam no $2^{\circ}$ e $3^{\circ}$ ano. Esse público de alunos tem uma faixa etária entre 14 e 18 anos já os professores que foram indagados encontram-se numa faixa etária entre 25 e 45 anos. Aplicação está relacionada a todas as disciplinas.

\section{Desenvolvimento}

Nesta seção será apresentado o processo utilizado para desenvolvimento da solução. O processo foi o Design Thinking para ambientes virtuais de aprendizagem móvel - DT- AVAM (SOUZA, SILVA, 2014). O processo é dividido em 3 fases: Imersão, Ideação e prototipação. Em cada fase ocorrem um conjunto de atividades. A seguir será apresentado o processo de desenvolvimento da BibliVirti:

\subsection{Fase 1 - Imersão}

\subsubsection{Levantar ideias}

Esta atividade foi realizada com o auxílio de uma técnica criativa chamada braistorming (OLIVEIRA et. al., 2010) onde os participantes envolvidos na amostra foram alunos(as) e professores(as) do ensino médio que atuam no $2^{\circ}$ e $3^{\circ}$ ano. Esse público de alunos tem uma faixa etária entre 14 e 18 anos já os professores que foram indagados encontram-se numa faixa etária entre 25 e 45 anos.

Antes da entrega dos questionários foi explicado a necessidade da colaboração de cada um(a) para o levantamento das ideias naquele momento. Posteriormente recebemos do público um total de 215 cartões insights, onde cada cartão continha: título, tema e fato a ser explorado. Desse total apenas 13 não contribuíram e 202 registros foram selecionados para análises e suas respectivas ideias.

\subsubsection{Analisar ideias}

A partir das informações levantadas, os dados foram analisados utilizando o NVivo (AMES, 2013) como ferramenta de apoio. A partir das informações escritas pelos alunos(as) e professores(as) as "palavras" foram retiradas dos textos e referenciadas por intermédio do software.

Após concluírem-se os registros, é momento em que será feita a categorização das ideias, é o instante em que irá se criar "conjuntos" de forma generalizada para se poder agrupar às ideias em comum dentre todos os registros dos usuários, a categoria que conter o maior número de registros, esta será a ideia do projeto.

Foram selecionados 13 temas (nós) mais referenciados nos cartões insights que os alunos e o professor citaram ser importantes no processo de ensino aprendizagem. Dentre 
eles a ideia mais referenciada foi a criação de uma aplicação que trabalhasse com conteúdos dos professores, disponibilizado material para que os alunos pudessem estudar.

\subsubsection{Organizar ideias}

Neste passo organizou-se as ideias com base na análise anterior realizada com a ferramenta NVivo, mapeando-as as mais criativas das menos criativas. Gerou-se um "mapa mental" onde do lado esquerdo estão registradas as ideias menos criativas e do lado direito as mais criativas, com maior grau de afinidade pelos usuários (figura 1).

Figura 1 - Mapa Mental.

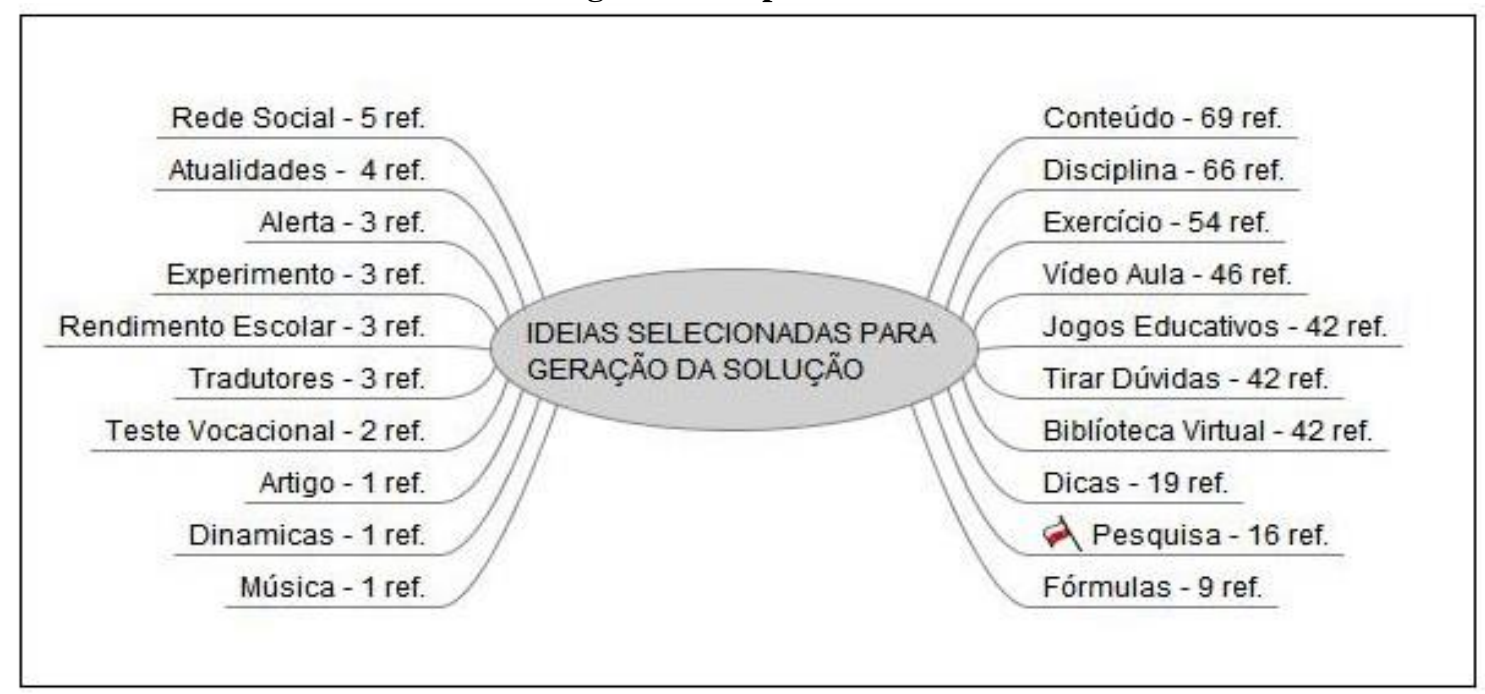

\subsection{Fase 2 - Ideação}

\subsubsection{Escolher ideia}

Esta atividade foi realizada baseada no mapa gerado na atividade anterior, onde de acordo com o grau de afinidade e similaridade de necessidades e desejos dos alunos e professor pode-se identificar que a proposta mais citada para o projeto foi a de um aplicativo que contenha e disponibiliza o conteúdo das disciplinas para que os alunos possam acessá-las. Como resultado foi proposto uma solução a qual denominamos BIBLIVIRTI.

\subsubsection{Criar Perfis}

Nesta atividade foram criados os perfis dos usuários relacionados à ideia escolhida. Utilizou-se uma técnica criativa chamada Personas (BATISTA et. al., 2013). Esta técnica adota pessoas fictícias para representar usuários de um serviço ou produto. As PERSONAS estão inseridas em cenários, histórias, que representam situações reais de uso.

Com base nos dados da pesquisa de campo exploratória e na entrevista semiestruturada com alunos e professores, identificou-se alguns comportamentos no que tange a percepção e utilização da tecnologia e a necessidade de identificar as principais características do aluno do ensino médio. A partir dos dados coletados criou-se um persona como mostra a figura 2. 


João tem 38 anos. É professor do ensino médio, onde tem uma vida
corrida trabalhando em mais de uma escola, procurando gerenciar
seu tempo para estudar, se mantendo atualizado, e dar atenção a sua
família. Faz uso da tecnologia na vida pessoal e profissional,
questiona que seu tempo é limitado. Acesso a internet para pesquisa,
E-mail e Powerpoint. Compartilha informações com colegas, alunos
e ex-alunos através do Facebook e E-mail. Achou interessante a
criação de um aplicativo e gostaria de um para ajudar na sala de aula

Baseada nas informações que foram categorizadas na fase 1 foi realizada a elicitação dos requisitos conforme mostra o quadro 1 e o quadro 2.

Quadro 1 - Classificação de algumas informações dos usuários a partir dos cartões.

\begin{tabular}{|l|l|}
\hline \multicolumn{1}{|c|}{ Identificação dos Cartão } & \multicolumn{1}{c|}{ Descrição } \\
\hline C04 & $\begin{array}{l}\text { Desenvolver um aplicativo, onde o } \\
\text { professor possa mandar as atividades e } \\
\text { conceitos do assunto diretamente para o } \\
\text { celular ou tablete do aluno, assim } \\
\text { poupando mais tempo para a explicação, } \\
\text { assim melhorando a qualidade do ensino. }\end{array}$ \\
\hline $\mathbf{C 4 7}$ & $\begin{array}{l}\text { A grande necessidade é achar os } \\
\text { conteúdos que esteja pronto, fácil acesso. }\end{array}$ \\
\hline $\mathbf{C 7 3}$ & Um aplicativo com os assuntos. \\
\hline $\mathbf{C 8 4}$ & $\begin{array}{l}\text { Um aplicativo que contenha o assunto de } \\
\text { todas as matérias que seja confiável. }\end{array}$ \\
\hline $\mathbf{C 8 8}$ & $\begin{array}{l}\text { Ter os assuntos que utilizaremos como se } \\
\text { fossem livros didáticos. }\end{array}$ \\
\hline $\mathbf{C 9 3}$ & Conteúdos. \\
\hline C94 & Acesso ao conteúdo. \\
\hline C106 & Conter assuntos e conteúdos resumidos. \\
\hline
\end{tabular}

No quadro 2 estão relacionados alguns requisitos funcionais:

Quadro 2 - Requisitos Funcionais

\begin{tabular}{|l|l|}
\hline Requisitos & Descrição \\
\hline RF01 - InserirConteúdo & $\begin{array}{l}\text { Deverá permitir que o professor possa } \\
\text { inserir os conteúdos. }\end{array}$ \\
\hline RF02 - Inserir Exercício & $\begin{array}{l}\text { Deverá permitir que o professor possa } \\
\text { inserir atividades. }\end{array}$ \\
\hline
\end{tabular}




\begin{tabular}{|l|l|}
\hline RF03 - InserirFórmulas & $\begin{array}{l}\text { Deverá permitir que o professor possa } \\
\text { inserir formulas relacionadas a sua } \\
\text { disciplina. }\end{array}$ \\
\hline RF04 - InserirDúvidas & $\begin{array}{l}\text { Deverá permitir que o aluno possa inserir } \\
\text { suas dúvidas relacionadas a matéria. }\end{array}$ \\
\hline RF05 - InserirVídeo & $\begin{array}{l}\text { Permite que o professor possa inserir } \\
\text { vídeos relacionados à matéria. }\end{array}$ \\
\hline RF06 - InserirResumo & Permitir o professor insira resumos. \\
\hline RF07 - InserirDicas & $\begin{array}{l}\text { Permite que o professor possa inserir } \\
\text { dicas. }\end{array}$ \\
\hline
\end{tabular}

\subsection{Fase 3 - Prototipação}

\subsubsection{Desenvolver Protótipo}

Esta atividade é o momento no qual as ideias abstratas ganham conteúdo formal e material. Aqui estão representados os requisitos levantados para apresentar a solução proposta. Foi utilizada uma ferramenta de Prototipação para realização desta atividade chamada Balsamiq Mockups.

\subsubsection{Refinar Protótipo}

Esta atividade de refinamento do protótipo foi realizada com a técnica Brainstorming destrutivo/construtivo, onde foram selecionados dois grupos. Onde um grupo continha três professores e o outro uns 15 alunos.

Por parte dos professores houve muitos elogios pelas funcionalidades e pela simplicidade do protótipo, e também um certo interesse em saber quando a aplicação vai estar pronta para uso.

Foi questionado sobre a possibilidade da inserção de simulados, que é uma atividade frequente na escola, além de perguntas sobre a funcionalidade da aplicação, como o sistema operacional que vai ser instalado a aplicação.

\subsubsection{Redesign da aplicação}

Após o refinamento do protótipo foi feito um novo design da aplicação e desenvolvido o protótipo de alta fidelidade com as novas funcionalidades sugeridas pelos usuários. $\mathrm{O}$ protótipo será apresentado na próxima seção com a definição das funcionalidades.

O protótipo foi desenvolvido na plataforma Android utilizando a linguagem Java, usando o Eclipse.

\subsubsection{Teste de Usabilidade}

Foram realizados testes de usabilidade para verificar a facilidade de aprendizado e a satisfação do usuário Para coleta dos dados foi utilizada a ferramenta Camtasia Studio e a aplicação de um questionário ao final da interação do usuário com as funcionalidades. Foram usados casos de uso para auxiliar o usuário no processo de interação. Dentre os usuários que realizaram os testes de casos de uso encontram-se cinco professores e dez alunos, onde cada um realizou duas ou mais funcionalidades (Requisitos) do protótipo.

A análise geral do teste constatou que os professores que realizaram os testes, apesar das limitações de interação do protótipo, todos se mostraram bastantes empolgados com o modelo de aplicação que está sendo proposto e se disseram muito ansiosos para 
com a implantação software. A participação dos usuários foi muito importante, onde eles puderam citar suas respectivas dúvidas e/ou idéias e validar a aplicação.

Em relação aos alunos também foram bastante participativos, os alunos se mostraram muito empolgados e interessados no modelo de software apresentado para os testes. Os alunos tiveram uma participação fundamental contribuindo também com suas sugestões, elogios e críticas, fazendo com que a aplicações sofresse alterações de fundamental importância para o uso dos alunos no dia-a-dia. Por fim, citaram estar muito ansiosos para que a aplicação seja implementada e os primeiros testes sejam realizados em seu cotidiano escolar.

\section{Apresentação do software}

Nesta seção serão apresentadas algumas telas do protótipo. Tipo de Licença de software gratuito.

Login: Para ter acesso ao software é necessário fazer login, o login será feito com o preenchimento do e-mail e senha do usuário e em seguida deverá clicar no botão entrar. Ao efetuar o login a tela grupo de estudos é exibida (Ver Fig. 3).

Grupo de Estudo: Fica visível os grupos de estudos que o usuário participa e os grupos no qual ele é o administrador, o usuário poderá procurar um novo grupo para participar, a busca pode ser feita pelo nome do grupo ou área de interesse, basta digitar a descrição e clicar no ícone lupa. O usuário também poderá criar seu próprio grupo de estudo clicando no ícone + onde dará acesso a tela novo grupo (Ver Fig. 4).

Novo Grupo de Estudo: Para criar um novo grupo de estudo deverá ser informado o nome do grupo, área de interesse e especificar se o grupo é público ou privado, o grupo sendo público qualquer usuário poderá ter acesso ao grupo e ao seu material de apoio sem autorização do administrador, caso o grupo seja privado deverá ser enviado uma solicitação para participar do grupo e só depois de aceito pelo administrador o usuário terá acesso ao material de apoio do grupo, feito isso basta apenas clicar no ícone do disquete que salvará (Ver Fig.5).

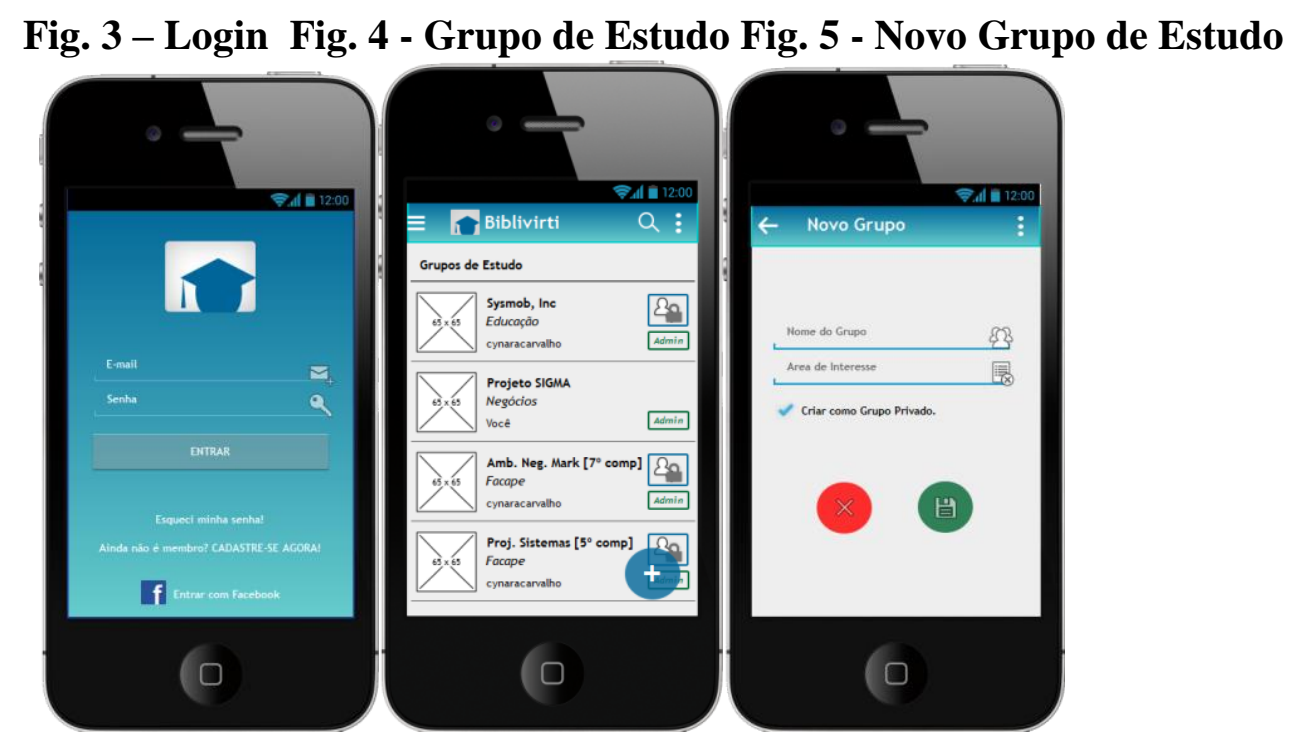




\section{CBIE-LACLO 2015}

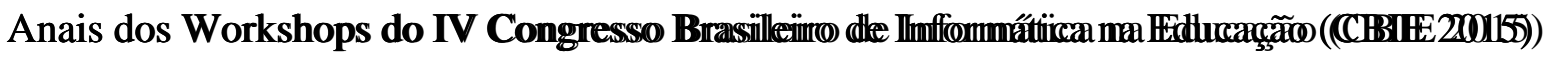

Material de Apoio: Ao selecionar um grupo de estudo abrirá a tela que exibirá o material de apoio ordenado por categoria e em cada categoria listará os 3 últimos matérias postados daquela categoria, na opção ver mais o usuário poderá ver todos os matérias daquela categoria, para inserir um novo material de apoio basta clicar no ícone + onde dará acesso a tela para cadastrar um novo material de apoio.(Ver Fig. 6).

Novo Material de Apoio:Para inserir um novo material de apoio deverá ser informado o tipo de material que se deseja inserir, uma descrição e anexar o material, feito isso basta apenas clicar no ícone do disquete que salvará (Ver Fig. 7).

Chat: Cada grupo possui um chat onde pode se tirar dúvidas com todos os membros do grupo ou apenas com o administrador (Ver Fig.8).

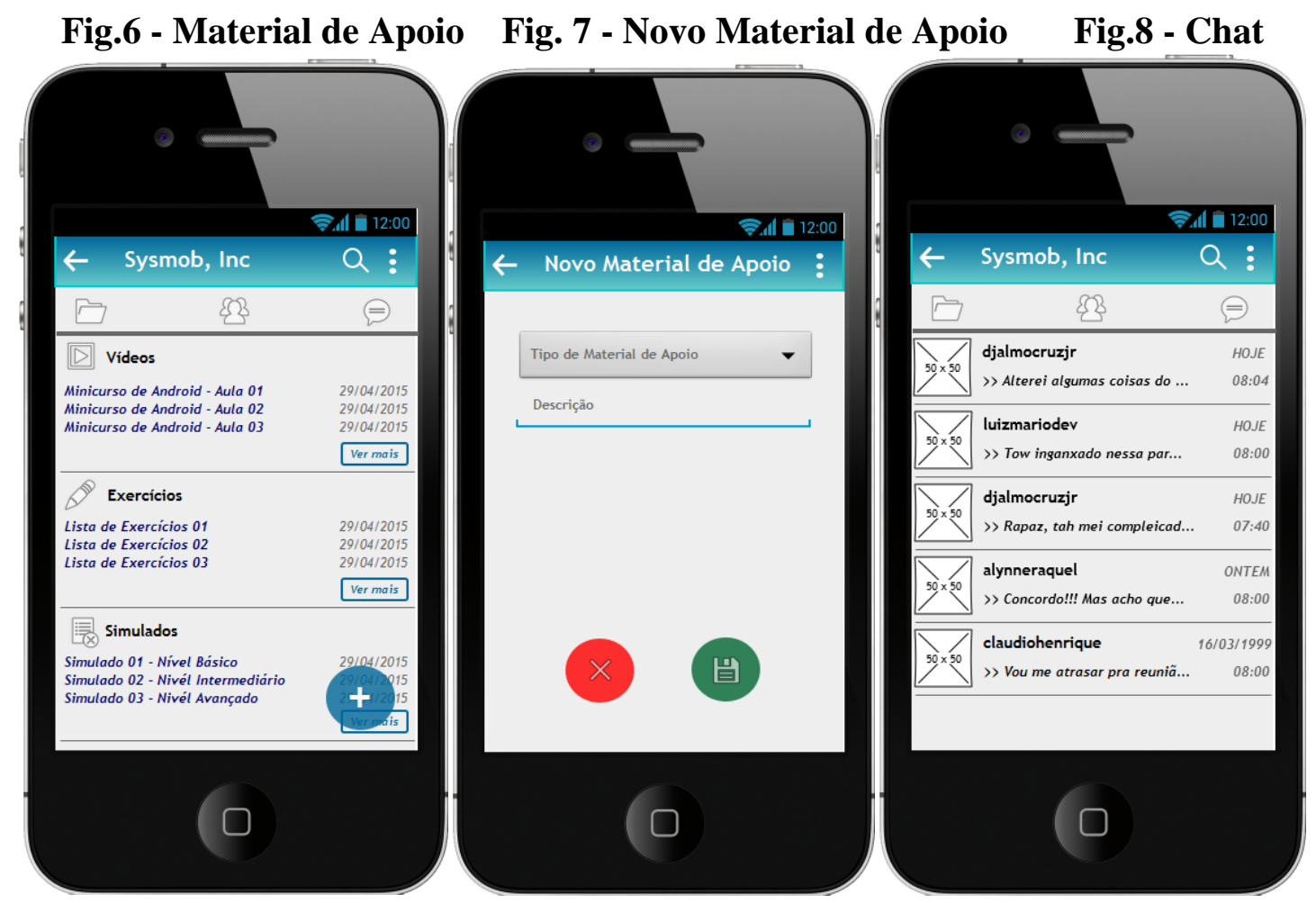

\section{Considerações finais}

O processo de desenvolvimento proposto nesse artigo surge com o intuito de ajudar no desenvolvimento de novas aplicações no âmbito da aprendizagem móvel.

No experimento os alunos e professores participam de todo o processo identificando as necessidades, propondo soluções, gerando e refinando requisitos. Os resultados indicaram também que a aplicação de técnicas de criatividade no processo trouxe benefícios e foi validada pelo número de ideias geradas. $\mathrm{O}$ processo de ensino e aprendizagem precisa assumir a participação dos estudantes e professores durante o desenvolvimento de AVAM para obter resultados inovadores.

Diversas aplicações de aprendizagem móvel exploram conteúdos, recursos de áudio e vídeo das aulas, como as citadas por (MARÇAL et al., 2010), mas não apresentam nenhuma forma de interação entre o aluno e o professor em sala de aula.

Para trabalhos futuros pretendemos: (i) implantar as soluções em um ambiente educacional de forma a avaliar o seu impacto no processo de ensino aprendizagem; (ii) 
avaliar se as soluções propostas neste trabalho atendem as características/requisitos pedagógicos; (iii) Testar a usabilidade do software.

Os usuários da escola, professores e alunos, também avaliaram as soluções geradas pelos grupos e demonstraram uma excelente aceitação pela solução apresentada, comprovando que o processo proposto consegue identificar a necessidade dos alunos e professores de forma mais assertiva e originar soluções mais inovadoras.

\section{Referencias}

Ames V. D. B. As possibilidades de uso do software de análise qualitativa NVivo.v. 1, n. 2, ago. 2013 -ARTIGOS. Disponível em: http://www.sociologiasplurais.ufpr.br/v1n2_artigo12.pdf.

Batista, C.A.T.; Souza, C.L.C.; Junqueira, R.P. Engenharia de Requisitos para aplicações Móveis. Monografia da pós-graduação de Engenharia de Requisitos. Centro de Informática. Universidade Federal de Pernambuco.2013.

Souza, Silva, 2014. An Experimental Study of the Use of Design Thinking as a Requirements Elicitation Approach for Mobile Learning Environments. CLEI Electronic Journal (CLEIej, ISSN 0717- 5000)accepted for publication.2014

Marçal,E.; Lima,L.; Melo, Jr.; Viana, W.;Andrade,R.; Ribeiro,J. W. Da Elicitação de Requisitos ao Desenvolvimento de Aplicações de Mobile Learning em Matemática. Simpósio Brasileiro de Informática na Educação. SBIE 2010.ISSN 2316-6533O. Disponível em: http://www.brie.org/pub/index. php/sbie/article/view/1441/1206.

Oliveira, C. C.; Oliveira, D. C.; Oliveira, C. F.; Cattelan,R. G.;Souza, J.N. Árvore de características de software educativo: Uma proposta de elicitação de requisitos pelo usuário. Simpósio Brasileiro de Informática na Educação. SBIE 2010. Disponível em: http://www.br-ie.org/pub/index.php/sbie/article/view/1517.

Portal Brasil; Projeto Educação Digital disponível em: http://www.brasil.gov.br/educacao/2012/02/professores-do-ensino-medio-deescolas-publicas-receberao-tablets-no-segundo-semestre 